\title{
miR-486 acts as an oncogene and potential prognostic biomarker in renal cell carcinoma
}

\author{
CHENGWEN SUN ${ }^{1 *}$, CAIHONG SUN ${ }^{2 *}$, YIBIN ZHOU $^{3 *}$, GANGLONG YANG $^{4}$, \\ GUANG LI $^{1}$, CONGMING XIANG ${ }^{1}$, XIQI DING ${ }^{1}$ and JIAN SUN ${ }^{1}$ \\ ${ }^{1}$ Department of Urology, Affiliated Hospital of Jiangnan University, Wuxi, Jiangsu 214062; \\ ${ }^{2}$ Department of Critical Care Medicine, People's Hospital of Rizhao, Rizhao, Shandong 276800; \\ ${ }^{3}$ Department of Urology, The Second Affiliated Hospital of Soochow University, Suzhou, Jiangsu 215004; \\ ${ }^{4}$ The Key Laboratory of Carbohydrate Chemistry and Biotechnology, Ministry of Education, \\ School of Biotechnology, Jiangnan University, Wuxi, Jiangsu 214000, P.R. China
}

Received November 14, 2018; Accepted June 13, 2019

DOI: $10.3892 / \mathrm{mmr} .2019 .10769$

\begin{abstract}
MicroRNAs (miRNAs) are well established key players in tumorigenesis. Their emergence as potential diagnostic and prognostic biomarkers for cancer has demonstrated the importance of miRNAs in cancer biology. Although miR-486 is implicated in many types of cancer, its role in renal cell carcinoma (RCC) remains undetermined. In the present study, real-time quantitative PCR (qPCR), wound scratch assay, cell proliferation assay, Transwell migration assay and flow cytometry were utilized to detect the miR-486 transcript and its role in proliferation, migration and apoptosis in RCC. The relationship between miR-486 expression and clinicopathological variables or overall survival was analyzed using 96 formalin-fixed paraffin-embedded (FFPE) RCC samples. The results of the present study revealed significant upregulation of miR-486 in RCC tissues and cell lines. Moreover, ectopic expression of miR-486 promoted cell proliferation, mobility and inhibited apoptosis in 786-O and ACHN cell lines. In addition, the Cox proportional hazard regression analysis revealed that patients with low expression of miR-486 exhibited a markedly longer overall survival in the univariate and multivariate analyses. In conclusion, our findings indicate that miR-486 may serve as a novel prognostic biomarker but may also be applied as a new therapeutic approach for the treatment of RCC.
\end{abstract}

Correspondence to: Dr Chengwen Sun or Professor Jian Sun, Department of Urology, Affiliated Hospital of Jiangnan University, 200 Huihe Road, Wuxi, Jiangsu 214062, P.R. China

E-mail: docpanda666@outlook.com

E-mail: sunjian999204@sina.com

*Contributed equally

Key words: microRNA, miR-486, oncogene, renal cell carcinoma, prognosis

\section{Introduction}

Renal cell carcinoma (RCC) is the most common solid lesion located within the kidney and represents $\sim 90 \%$ of all renal malignancies (1). The prevalence of the classic triad of hematuria, flank pain and palpable abdominal mass in RCC patients is actually lower than $10 \%$, even $6 \%$ (2). Therefore, approximately $20-30 \%$ of patients present with metastatic RCC at initial diagnosis, and the recurrence rate of post-surgical treatment cases is $20-30 \%$ (3). RCC is typically resistant to radiation therapy and chemotherapy, and therefore surgery remains the only curative treatment for $\operatorname{RCC}(1,4)$. Recently, much attention has shifted to targeted therapies for which either sunitinib or pazopanib is the standard first-line treatment for RCC (5). As the clinical effects of these therapies are not effective, it is crucial to develop more effective therapeutic strategies against RCC.

MicroRNAs (miRNAs, miRs) are a class of non-coding RNAs of 17-24 nucleotides, which mediate cell differentiation, proliferation, migration, apoptosis and invasion by targeting the 3'-untranslated region (UTR) of mRNA post-transcriptionally (6-8). Aberrant expression of several miRNAs has been implicated in the tumorigenesis of RCC, including as miR-21 (9), miR-23a (10), miR-566 (11) and miR-425-5p (12). Since its discovery in the human fetal liver (13), miR-486 has been reported in several malignancies, including esophageal cancer (14), non-small cell lung cancer (NSCLC) (15), colorectal cancer (CRC) (16) and osteosarcoma (17). However, miR-486 and its role in RCC remain largely unknown.

In the present study, miR-486 expression was evaluated in RCC tissues and RCC cell lines. The effects of miR-486 on kidney cancer cell proliferation, invasion and apoptosis were also investigated. Finally, the association between miR-486 expression and outcome in RCC patients was explored.

\section{Materials and methods}

Specimens. Samples including 47 paired RCC tissue samples and adjacent normal tissue samples (extracted at a distance of $5-\mathrm{cm}$ from the RCC tissue) were obtained from 
the Department of Urology, Affiliated Hospital of Jiangnan University (Wuxi, China) from May 2013 to April 2015. These patients consisted of 29 males and 18 females, ranging in age from 21 to 73 years old. Immediately after resection, the specimens were maintained in RNAlater ${ }^{\circledR}$ (Qiagen, Inc.) and stored at $-80^{\circ} \mathrm{C}$ until further use. All participants provided written informed consent, and the study was approved by the Ethics Committee of the Affiliated Hospital of Jiangnan University. Table I lists the clinicopathological features of the 47 patients enrolled in the study. In addition, 96 formalin-fixed paraffin-embedded (FFPE) RCC tissues were supplied by the Department of Pathology, Affiliated Hospital of Jiangnan University between February 2011 and January 2014. These patients consisted of 63 males and 33 females, ranging in age from 21 to 78 years old. Clinicopathological characteristics of the FFPE samples are presented in Table II. These are two different batches of specimens. Table I lists fresh tissue samples from 47 patients with renal carcinoma (including renal carcinoma and adjacent normal tissue). Table II documents the paraffin tissue samples from 96 patients with renal cancer.

RNA extraction, cDNA synthesis and reverse transcription-quantitative PCR (RT-qPCR). Total RNA was extracted by using TRIzol (Invitrogen; Thermo Fisher Scientific, Inc.) according to the manufacturer's instructions, purified by using the RNeasy Maxi kit (Qiagen, Inc.) and quantified on a NanoDrop 2000c (Thermo Fisher Scientific, Inc.). cDNA was synthesized by reverse transcription according to the instructions of an miScript II RT kit (Qiagen, Inc.). The expression of miR-486 was detected using an miScript SYBR ${ }^{\circledR}$ Green PCR kit (Qiagen, Inc.) on the Roche Lightcycler ${ }^{\circledR} 480$ Real-Time PCR System (Roche Diagnostics). The thermocycling steps were: $95^{\circ} \mathrm{C}$ for $15 \mathrm{~min}$, followed by 40 cycles of $94^{\circ} \mathrm{C}$ for $15 \mathrm{sec}$, $55^{\circ} \mathrm{C}$ for $30 \mathrm{sec}$ and $72^{\circ} \mathrm{C}$ for $30 \mathrm{sec}$. The primer sequences used were: miR-486-5p forward, 5'-ACACTCCAGCTGGGT CCTGTACTGAGCTGCCC-3' and reverse, 5'-CTCAACTGG TGTCGTGGAGTCGGCAATTCAGTTGAGCCCCGAG-3'; U6 forward, 5'-CTCGCTTCGGCAGCACA-3' and reverse, 5'-AACGCTTCACGAATTTGCGT-3'. U6 was regarded as the internal control in this study. Relative expression of miR-486 was analyzed by the $2^{-\Delta \Delta \mathrm{Cq}}$ method (18).

Cell culture and transfection. Immortalized normal human kidney cells (HK2) and RCC cell lines (ACHN, 786-O, Caki-1) were supplied by the Key Laboratory of Carbohydrate Chemistry and Biotechnology (Wuxi, China). Cell lines were cultured and maintained according to the instructions provided by the American Type Culture Collection. Cells were cultured in at $37^{\circ} \mathrm{C}$ in a $5 \% \mathrm{CO}_{2}$ humidified incubator. ACHN and 786-O cells were transiently transfected with $100 \mathrm{pmol}$ miR-486 mimic (forward, 5'-ACACUCCAGCUGGGUCCU GUACUGAGCUGCCC-3' and reverse, 5'-GGCCACCGC CGAGCGGACUU-3') or miR-negative control (NC; forward, 5'-UUCUCCGAACGUGUCACGUTT-3' and reverse, 5'-ACG UGACACGUUCGGAGAATT-3') using Lipofectamine 2000 (Invitrogen; Thermo Fisher Scientific, Inc.) and Opti-MEM ${ }^{\circledR}$ (Gibco; Thermo Fisher Scientific, Inc.) following the manufacturer's instructions. Following transfection, ACHN or 786-O cells were starved for $6 \mathrm{~h}$ before being transferred to DMEM (for ACHN cells) or RPMI-1640 (for 786-O cells; both Gibco; Thermo Fisher Scientific, Inc.) with 10\% FBS (Gibco; Thermo Fisher Scientific, Inc.) and 1\% glutamine (Gibco; Thermo Fisher Scientific, Inc.). Transfection efficiency was measured via RT-qPCR analysis. miR-486 mimic and NC were synthesized by Shanghai GenePharma Co., Ltd.

CCK-8 assay. Proliferation of $\mathrm{ACHN}$ and 786-O cells was assessed using a Cell Counting Kit-8 (CCK-8; Beyotime Institute of Biotechnology). Briefly, $\sim 10,000$ cells seeded in 96-well plates were transfected with miR-486 mimic or NC. CCK-8 (10 $\mu \mathrm{l})$ was added into each well and incubation was carried out for $30 \mathrm{~min}$. Absorbance was then assessed at $450 \mathrm{~nm}$ (with $620 \mathrm{~nm}$ as the reference wavelength) at $0,24,48$ and $72 \mathrm{~h}$ on an ELISA microplate reader (Bio-Rad Laboratories, Inc.).

Transwell assays. Transwell inserts were used to assess migration and invasion of the ACHN and 786-O cells. For the migration assay, $\sim 3 \times 10^{4}$ cells were seeded in a 24-well plate and transfected with miR-486 mimic or NC as described above. At $24 \mathrm{~h}$ later, $\sim 3 \times 10^{4}$ cells were seeded into each upper Transwell chamber (BD Biosciences). A volume of $600 \mu \mathrm{l}$ DMEM with $10 \%$ FBS and $1 \%$ glutamine was added to the bottom Transwell chamber. For the invasion assay, cells were seeded into a Matrigel-coated upper chamber of the Transwell inserts. After incubation for $48 \mathrm{~h}$, the cells in the lower chamber were fixed in $0.1 \%$ paraformaldehyde and stained with $4 \%$ crystal violet (both for $25 \mathrm{~min}$ at room temperature), and observed by a light microscope at magnification, $\mathrm{x} 100$.

Wound healing assay. Migration of the ACHN and 786-O cells was also determined by the wound healing assay. Cells $\left(\sim 10^{5}\right)$ were seeded in 6 -well plates and after $24 \mathrm{~h}$ were respectively transfected according to the manufacturer's instructions. A sterile 1-ml pipette tip was used to scratch a vertical horizontal line. Serum-free medium was added after the cells were scratched for excluding cell proliferation. Images of the scratches at 0,12 and $24 \mathrm{~h}$ were captured by a light microscope at magnification, x100. The assay was repeated at least three times.

Flow cytometry. Apoptosis analysis of the ACHN and $786-\mathrm{O}$ cells was carried out by flow cytometry. Cells $\left(\sim 10^{5}\right)$ were seeded in each well of a 6 -well plate and transfected as described above. After $48 \mathrm{~h}$, the cells were harvested and washed twice in cold PBS, resuspended in $100 \mu 11 \mathrm{X}$ binding buffer with $5 \mu \mathrm{l}$ Annexin V-FITC (Invitrogen; Thermo Fisher Scientific, Inc.) and $5 \mu \mathrm{l}$ propidium iodide (PI, Invitrogen; Thermo Fisher Scientific, Inc.) and stained for $15 \mathrm{~min}$ at room temperature in a dark place. Thereafter, $400 \mu \mathrm{l}$ of cold $1 \mathrm{X}$ binding buffer was added into each tube and apoptosis was assessed by flow cytometry (EPICS XL-4; Beckman Coulter, Inc.). FlowJo 7.6.1 (FlowJo LLC) was used to analyze the apoptotic rate.

Statistical analysis. All assays were repeated at least three times. All the statistical analyses were performed using SPSS 23.0 (IBM Corp.). Data are presented as the mean \pm standard deviation (SD). Expression of miR-486 in clinical specimens and different cell lines was analyzed using paired t-tests and 
Table I. Clinicopathological features of the RCC patients $(\mathrm{N}=47)$.

\begin{tabular}{lc}
\hline Characteristics & Data \\
\hline $\begin{array}{l}\text { Age, mean (range) in years } \\
\text { Sex, } \mathrm{n}\end{array}$ & $50(21-73)$ \\
Male/female & $29 / 18$ \\
Tumor stage, & \\
T1/T2/T3 + T4 & $22 / 15 / 10$ \\
$\begin{array}{l}\text { Fuhrman grade, } \mathrm{n} \\
\text { I/II/III/IV }\end{array}$ & $17 / 20 / 7 / 3$ \\
$\begin{array}{l}\text { AJCC clinical stage, n } \\
\text { I/II/III + IV }\end{array}$ & $19 / 11 / 17$ \\
\hline $\begin{array}{l}\text { AJCC, American Joint Committee on Cancer; RCC renal cell carci- } \\
\text { noma. }\end{array}$
\end{tabular}

ANOVA followed by Dunnett's test, respectively. Student's t-test, Fisher's exact test or Pearson $\chi^{2}$ test were used to analyze the association between miR-486 expression and clinicopathological variables. The correlation between miR-486 expression and clinicopathological variables or survival was analyzed using Cox proportional hazard regression analysis. Kaplan-Meier curves were used to plot overall survival. A value of $\mathrm{P}<0.05$ was considered to be indicative of a statistically significant result.

\section{Results}

miR-486 is upregulated in RCC tissues and RCC cell lines. RT-qPCR analysis revealed higher transcript abundance of miR-486 in RCC tissue samples when compared with that in the adjacent normal tissues ( $\mathrm{P}<0.001$; Fig. 1A). Similarly, relative expression of miR-486 in RCC cell lines was significantly higher than that noted in the normal HK2 cells (Fig. 1B).

miR-486 promotes cell proliferation. The CCK-8 assay was used to assess proliferation in vitro. Data showed that overexpression of miR-486 significantly increased the proliferation of the 786-O and ACHN cell lines compared with cells in the NC groups (Fig. 1C and D). The results indicated that miR-486 promotes cell proliferation.

miR-486 is a potential prognostic marker for $R C C$. The association between miR-486 expression and clinicopathological characteristics was analyzed in 96 FFPE renal cancer samples. As presented in Table II, there were no significant assocations between miR-486 expression and any clinical characteristics $(\mathrm{P}>0.05)$; however, it was revealed that the survival of patients with RCC was significantly associated with tumor stage $(\mathrm{P}<0.001)$ and miR-486 expression $(\mathrm{P}<0.05)$, but not gender, age or tumor size (Table III). Univariate and multivariate analyses showed that patients with low expression of miR-486 had a longer overall survival (OS; $\mathrm{P}<0.05$ ). Similarly, Kaplan-Meier survival analysis showed that patients with low miR-486 expression had longer OS than those with high expression $(\mathrm{P}=0.008$; Fig. $1 \mathrm{E})$.
Table II. Association between miR-486 expression level ${ }^{\mathrm{a}}$ and the clinical characteristics of the FFPE renal cancer samples $(\mathrm{N}=96)$.

\begin{tabular}{lllll}
\hline & & \multicolumn{2}{c}{ No. of patients } & \\
\cline { 3 - 4 } Variable & Total & High & Low & P-value $^{\mathrm{b}}$ \\
\hline Sex & & & & \\
Male & 63 & 33 & 30 & 0.519 \\
Female & 33 & 15 & 18 & \\
Age (years) & & & & \\
$\leq 60$ & 69 & 33 & 36 & 0.496 \\
$>60$ & 27 & 15 & 12 & \\
Tumor size (cm) & & & & \\
$\leq 4.0$ & 37 & 16 & 21 & 0.294 \\
$>4.0$ & 59 & 32 & 27 & \\
Tumor stage & & & & \\
I + II & 71 & 35 & 36 & 0.816 \\
III + IV & 25 & 13 & 12 & \\
\hline
\end{tabular}

${ }^{\mathrm{a} C u t-o f f}$ point was the median level. ${ }^{\mathrm{b}} \mathrm{Calculated}$ using Fisher's exact test or Pearson $\chi^{2}$ test.

miR-486 promotes cell mobility. In vitro assessment of migration by wound healing and Transwell migration assays revealed that ectopic expression of miR-486 significantly increased migration of the 786-O and ACHN cells compared with that noted in the corresponding controls (Figs. 2 and 3). Overexpression of miR-486 resulted in increased invasiveness of 786-O $(\mathrm{P}<0.01)$ and ACHN $(\mathrm{P}<0.01)$ cells when compared with the NC group. These results indicated that miR-486 promotes cell mobility.

miR-486 inhibits cell apoptosis. Flow cytometry was used to detect apoptosis in vitro. In the present study, early apoptosis (the Q3 region) was regarded as an indicator of apoptosis and was used to calculate the apoptotic rate. As shown in Fig. 4, the apoptotic rate of 786-O (Fig. 4C) cells in the group transfected with miR-486 mimic was significantly decreased compared with the $\mathrm{NC}$ group $(5.377 \pm 0.950$ vs. $14.406 \pm 1.000 \%$; $\mathrm{P}<0.05)$, as was the apoptotic rate of ACHN (Fig. 4D) cells in the group transfected with miR-486 mimic compared with the NC $(7.403 \pm 0.637$ vs. $15.633 \pm 1.365 \%$; $\mathrm{P}<0.05)$. Thus, the results indicated that overexpression of miR-486 decreased the apoptosis rate in 786-O and ACHN cells.

\section{Discussion}

Renal cell carcinoma (RCC) is a common malignant tumor and accounts for 3-5\% of all malignant diseases (19). Due to its late diagnosis and insensitivity to radiotherapy and chemotherapy, the prognosis of RCC is extremely poor (4). Although studies have identified many of the genetic and epigenetic changes associated with tumorigenesis of RCC, the complete understanding of the molecular mechanisms of RCC pathogenesis is still unclear. Playing an important role in tumorigenesis, miRNAs suppress gene expression 
A

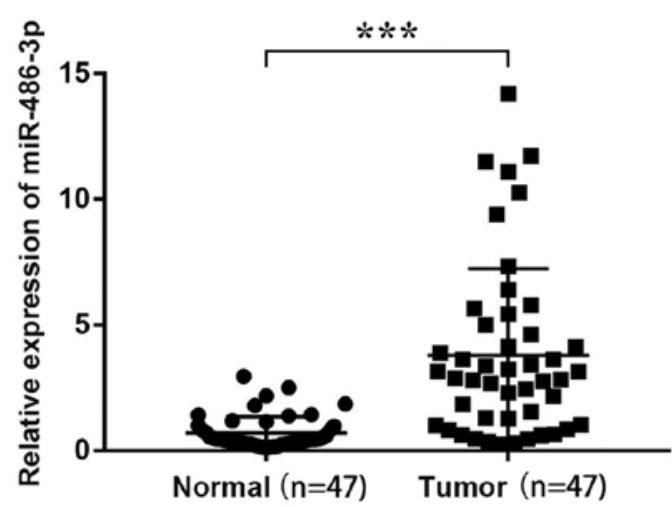

C

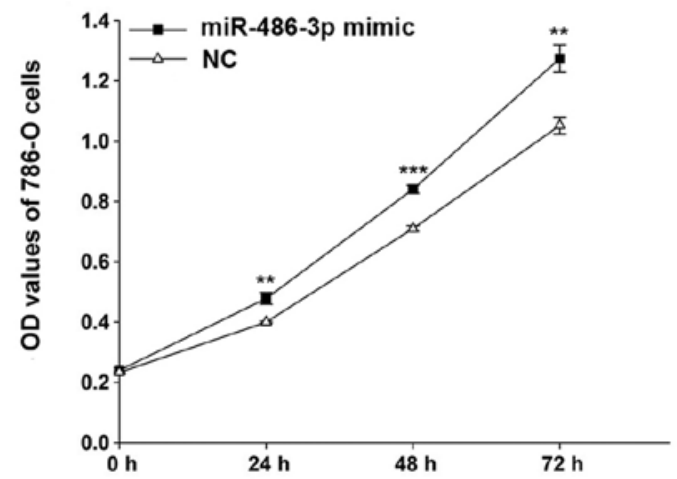

E

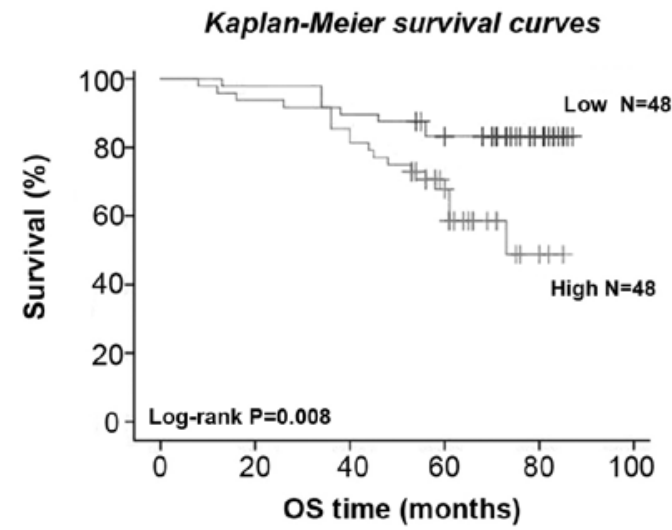

B

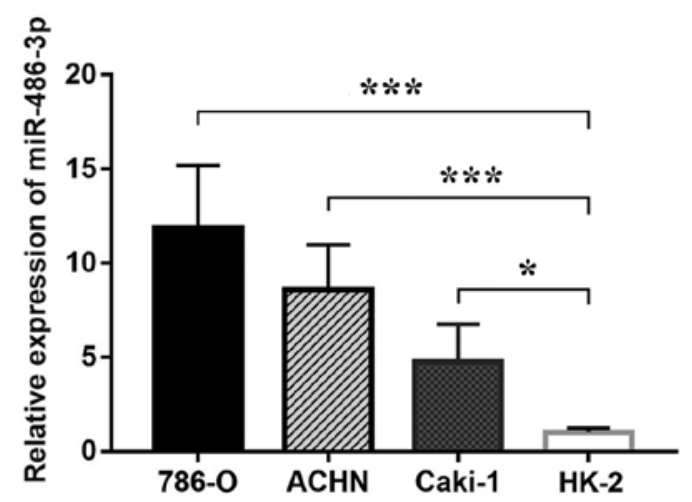

D

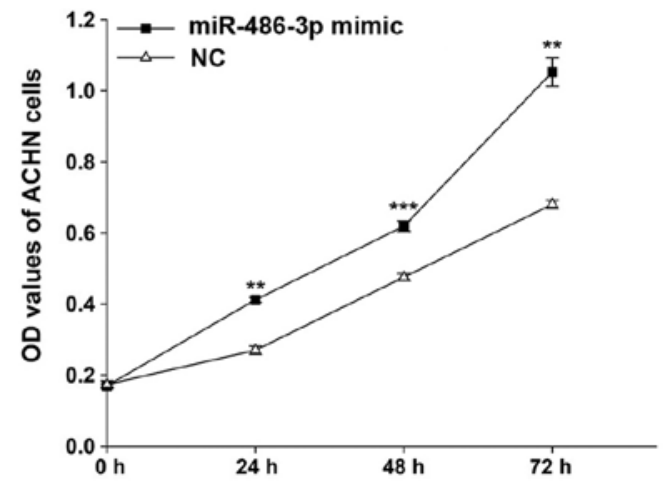

Figure 1. Expression of miR-486 in RCC. (A) Relative expression of miR-486 in RCC and normal tissues. (B) Relative expression of miR-486 in RCC cell lines (786-O, ACHN, Caki-1) and in normal cell line HK-2. Proliferation of (C) 786-O and (D) ACHN cells transfected with miR-23a-3p mimic or NC. (E) Kaplan-Meier survival curves of OS for patients with low or high miR-486 expression. ${ }^{*} \mathrm{P}<0.05,{ }^{* *} \mathrm{P}<0.01,{ }^{* * *} \mathrm{P}<0.001$. RCC, renal cell carcinoma; OS, overall survival.

by binding to the 3 '-UTR of target mRNAs (20) and as a result can modulate various cellular processes including cell viability (21), proliferation (10), migration (12), invasion (22), apoptosis (23), epithelial-mesenchymal transition (EMT) (24) and self-renewal of tumor stem cells (25).

Studies have demonstrated miR-486 as a driver of various types of cancer. Zhang et al (16), found that miR-486-5p inhibited the migration and invasion of colorectal cancer (CRC) cells by binding to PIK3R1. As a tumor suppressor, miR-486 suppressed cell invasion and EMT by targeting PIM in osteosarcoma (26) and mitigated prostate cancer metastasis by targeting Snail and regulating EMT (27). However, there are few reports concerning the oncogenic functions of miR-486. One such study by Gao et al (15), reported the oncogenic ability of miR-486-5p in the progression of non-small cell lung cancer (NSCLC) by targeting the tumor-suppressor PTEN. In contrast, Shao et al (28) reported that miR-486-5p functions as a tumor suppressor in NSCLC by directly targeting the oncogene CDK1. This disparity in findings warrants further investigation on the function of miR-486 in NSCLC.

In the present study, it was demonstrated that miR-486 is upregulated in RCC tissues and cell lines by RT-qPCR, which is in line with the findings of Goto et al (29). Moreover, ectopic expression of miR-486 promoted proliferation, migration, and invasion and suppressed apoptosis of the ACHN and 786-O cells.

Accumulating evidence suggests that miR-486 can be an ideal prognostic and diagnostic biomarker in various types of cancer. Jiang et al (30) revealed that low miR-486-3p and miR-103a-3p expression was respectively correlated with shorter 
A
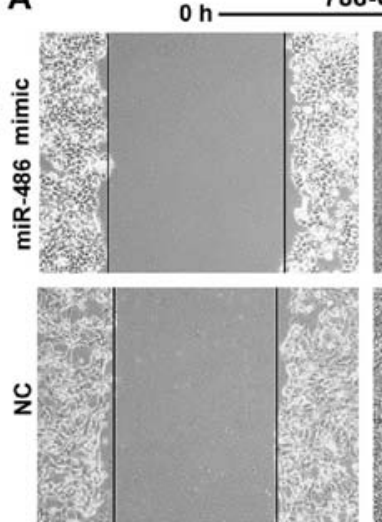

C
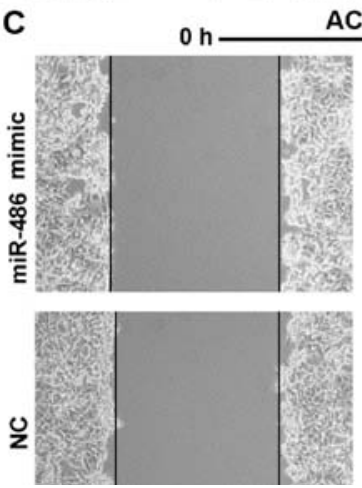

86-0
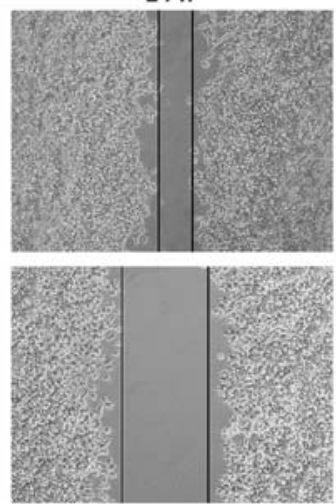

$\mathrm{ACHN}$
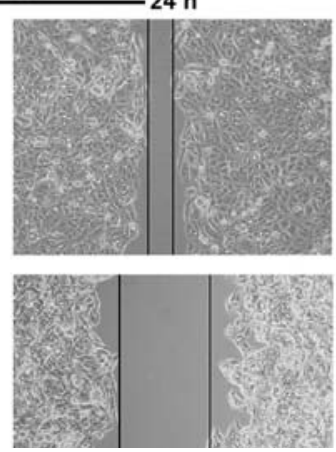

B

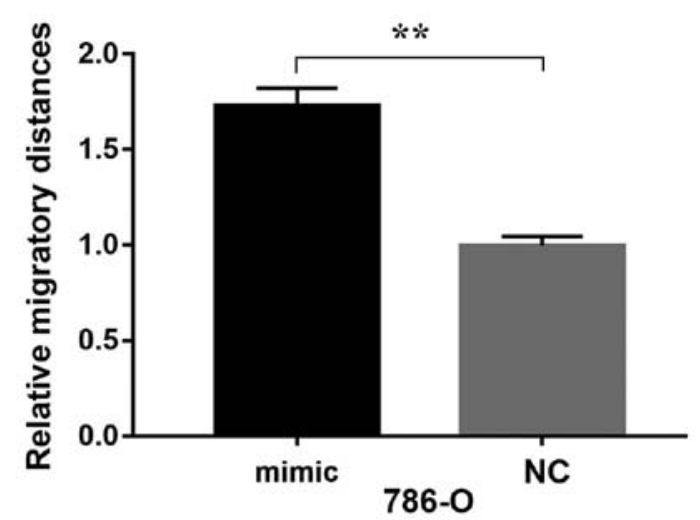

D

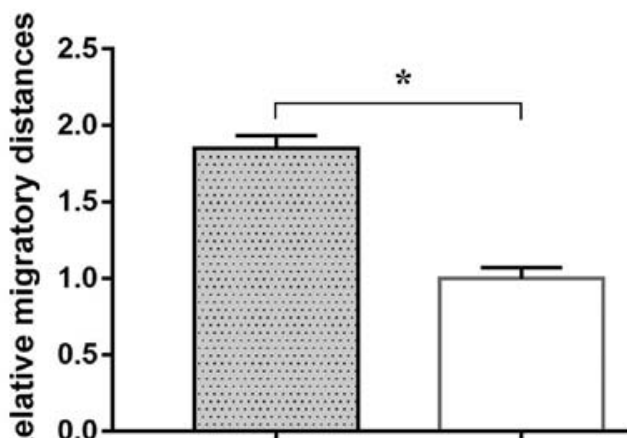

Figure 2. Effects of miR-486 on renal cell carcinoma cell migration. (A) Representative images showing migration of 786-O cells, as determined via wound healing assays. Magnification, x100. (B) Quantification of relative migration in 786-O cells transfected with miR-486 mimic or NC. (C) Representative images of migration of ACHN cells. Magnification, x100. (D) Quantification of relative migration in ACHN cells transfected with miR-486 mimic or NC. ${ }^{~} \mathrm{P}<0.05$, ${ }^{* *} \mathrm{P}<0.01$.

A

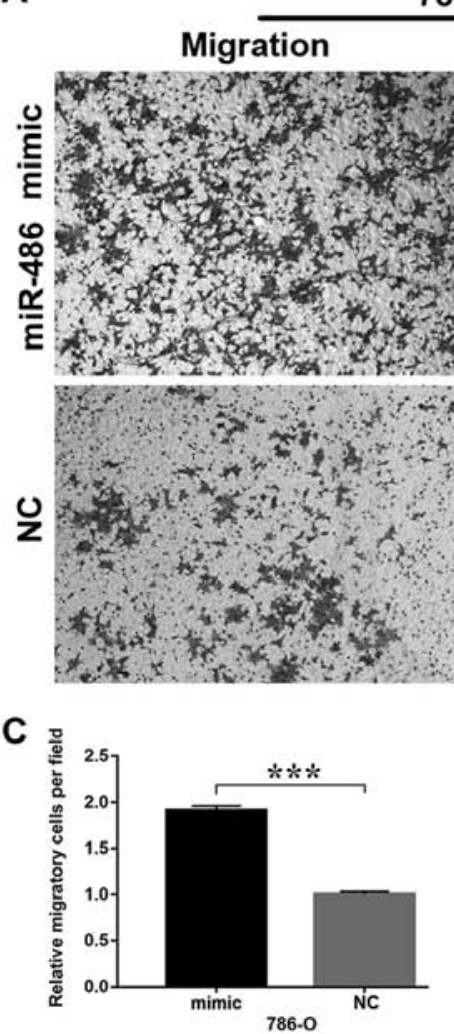

$786-0$
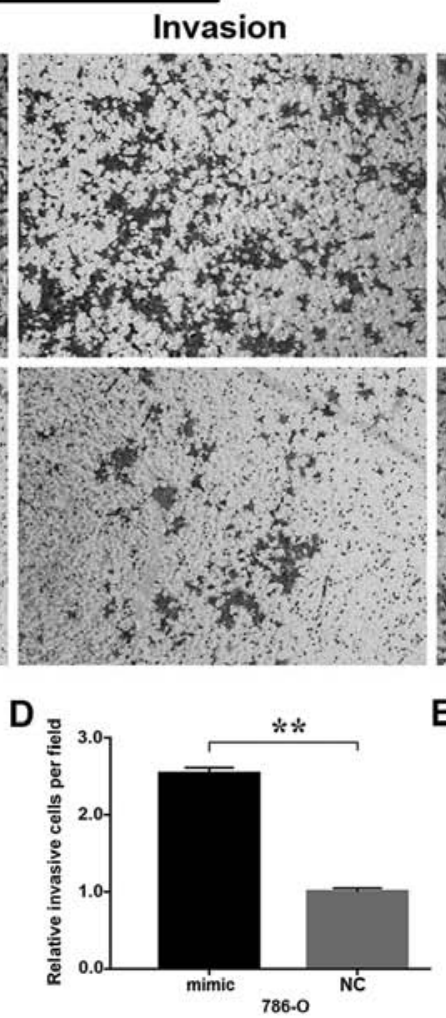

B
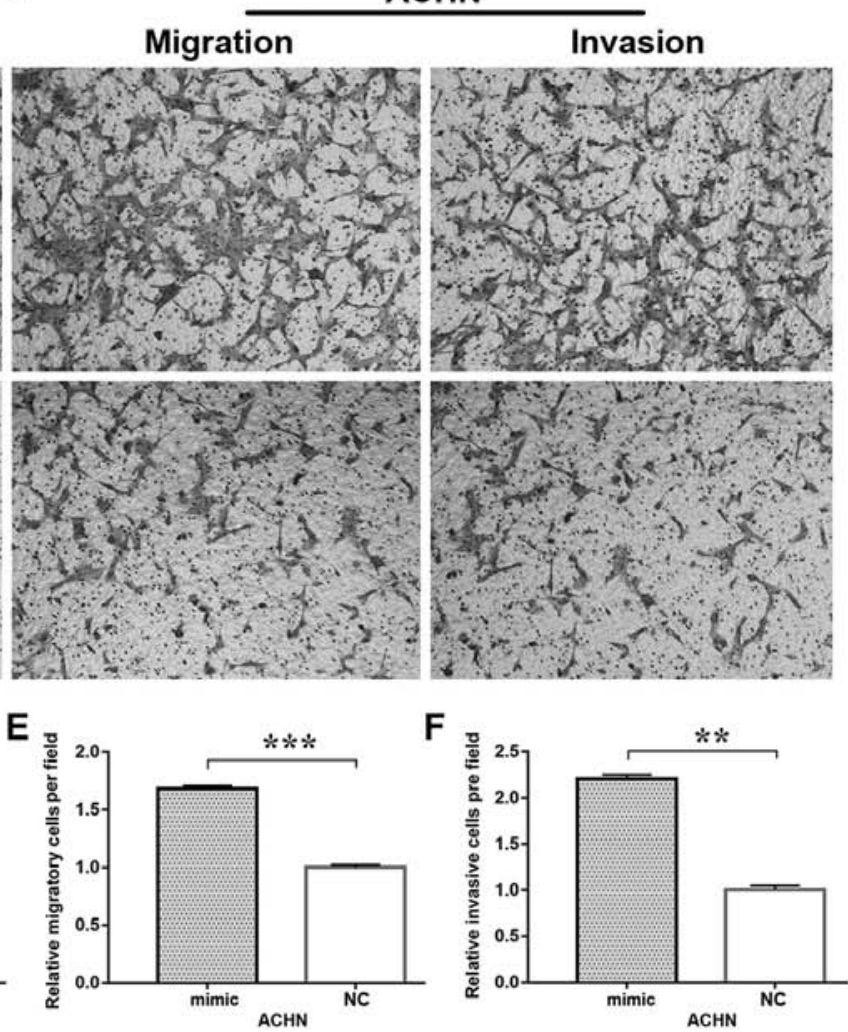

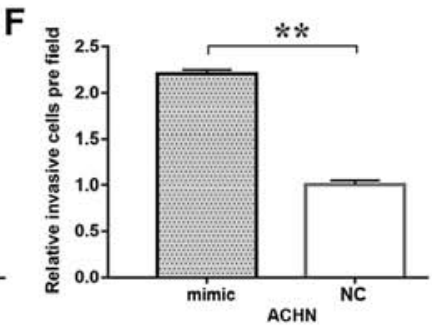

Figure 3. Effects of miR-486 on renal cell carcinoma cell migration and invasion. (A) Representative images of the migration and invasion of 786-O cells, as determined via Transwell assays. Magnification, x100. (B) Representative images of the migration and invasion of ACHN cells. Magnification, x100. (C and D) Relative migratory and invasive 786-O cells transfected with miR-486 mimic or NC per field. (E and F) Relative migratory and invasive ACHN cells transfected with miR-486 mimic or NC per field. ${ }^{* *} \mathrm{P}<0.01,{ }^{* * *} \mathrm{P}<0.001$. 
Table III. miR-486 expression and RCC patient survival.

\begin{tabular}{|c|c|c|c|c|}
\hline \multirow[b]{2}{*}{ Variable } & \multicolumn{2}{|c|}{ Univariate analysis } & \multicolumn{2}{|c|}{ Multivariate analysis } \\
\hline & $\mathrm{HR}(95 \% \mathrm{CI})$ & P-value & $\mathrm{HR}(95 \% \mathrm{CI})$ & P-value \\
\hline Sex (female vs. male) & $0.625(0.264-1.477)$ & 0.284 & $0.661(0.271-1.613)$ & 0.363 \\
\hline Age (years) ( $\leq 60$ vs. $>60)$ & $0.934(0.409-2.135)$ & 0.872 & $1.269(0.545-2.954)$ & 0.581 \\
\hline Tumor size $(\mathrm{cm})(\leq 4.0$ vs. $>4.0)$ & $0.721(0.324-1.607)$ & 0.424 & $0.728(0.323-1.638)$ & 0.442 \\
\hline Tumor stage (I + II vs. III + IV) & $0.055(0.022-0.139)$ & $<0.001$ & $0.057(0.022-0.143)$ & $<0.001$ \\
\hline miR-486-3p (low vs. high) & $0.342(0.148-0.790)$ & 0.012 & $0.398(0.170-0.929)$ & 0.033 \\
\hline
\end{tabular}

HR, hazard ratio; 95\% CI, 95\% confidence interval; RCC, renal cell carcinoma.

A

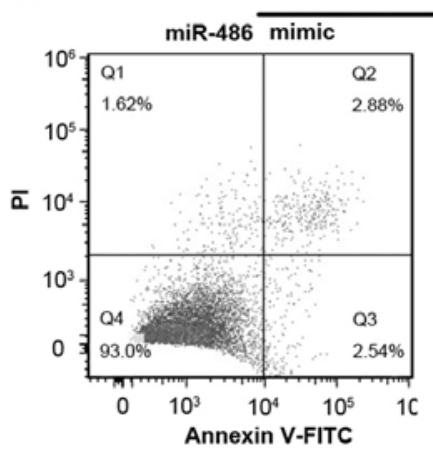

C

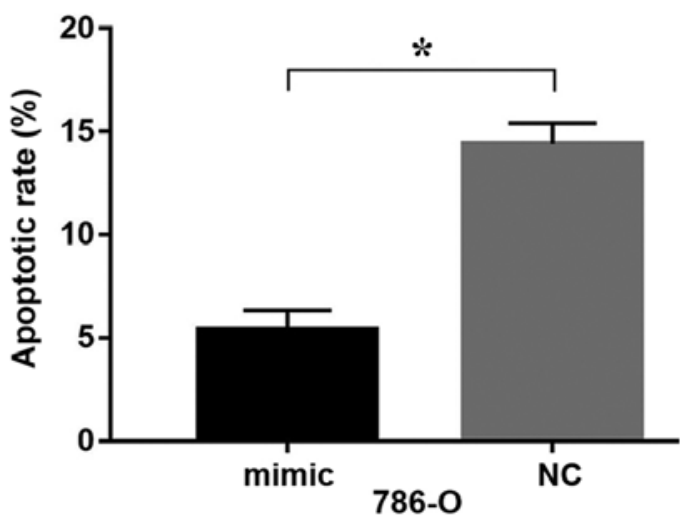

B
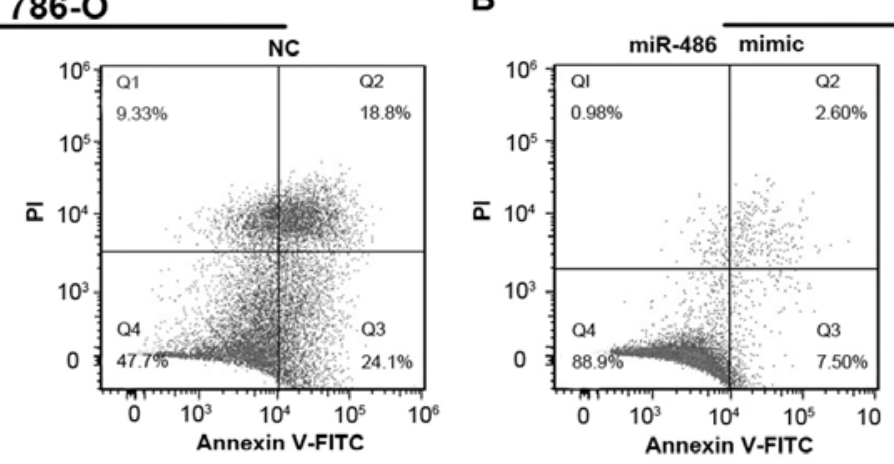

$\mathrm{ACHN}$

D

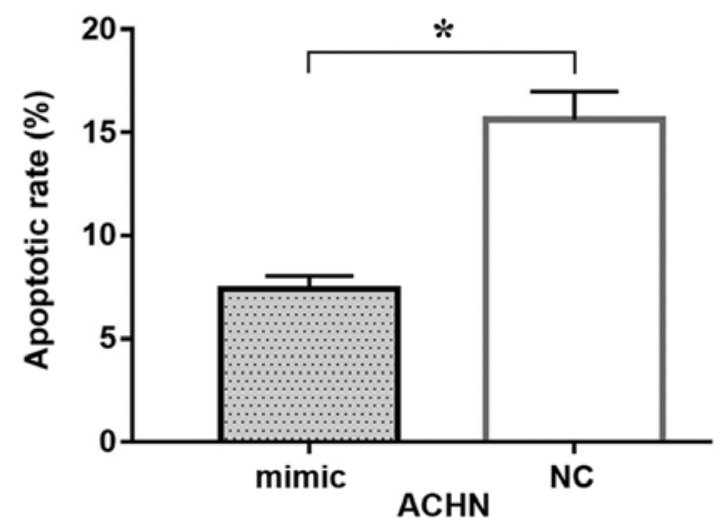

Figure 4. Effects of miR-486 on the apoptosis of renal cell carcinoma cells. Representative dot plots of Annexin V/PI staining in (A) 786-O and (B) ACHN cells transfected with miR-486 mimic or NC as etermined via flow cytometry. Quantification of early apoptosis in (C) 786-O and (D) ACHN cells transfected with miR-486 mimic or NC. ${ }^{*} \mathrm{P}<0.05$.

overall survival (OS) of patients with muscle-invasive bladder cancer (MIBC). Similarly, Ren et al (31) revealed that low or unchanged miR-486-5p predicted poor prognosis in patients with esophageal squamous cell carcinoma and gastric cancer, which was contrary to our finding that elevated miR-486 indicated a remarkably shorter OS in RCC patients, which also suggested its potential as a prognostic marker for RCC. Li et al (32), found that serum miR-486-5p serves as a diagnostic biomarker for cervical cancer with an $\mathrm{AUC}=0.90$. It was reported that compared to traditional urine cytology, the four-miRNA signature (miR-422a-3p, miR-486-3p, miR-103a-3p and miR-27a-3p) displayed higher accuracy in predicting MIBC (30). Furthermore, miR-486 proved to be a potential blood-based biomarker for early diagnosis and recurrence of NSCLC (33).
However, there are several limitations to our study. Firstly, to better verify our conclusion, we must complete functional experiments to determine how an miR-486 inhibitor regulates RCC cell proliferation and migration. Secondly, in the present study, miR-486 expression was found to be associated with patient survival; however, miR-486 expression was not associated with tumor stage. This may be due to the lack of tumor specimens of T3 and T4, especially T4. Further investigation of the relationship between miR-486 and renal cancer tumor staging using a higher number of T3 and T4 tumor samples will be carried out.

In conclusion, it was demonstrated that miR-486 was upregulated in RCC tissues and cell lines, and overexpression of miR-486 was associated with a poor prognosis of 
RCC patients. In the present study, miR-486 acted as an oncogene and promoted proliferation, migration, invasion and suppressed apoptosis. With a better understanding of its function, miR-486 may emerge as a potential prognostic marker and therapeutic target in the treatment of RCC.

\section{Acknowledgements}

Not applicable.

\section{Funding}

No funding was received.

\section{Availability of data and materials}

The analyzed datasets generated during the present study are available from the corresponding author on reasonable request.

\section{Authors' contributions}

$\mathrm{ChS}$ and $\mathrm{CaS}$ carried out the molecular genetic studies and drafted the manuscript. JS and YZ participated in the design of the study. GY and GL performed the statistical analysis. CX and $\mathrm{XD}$ participated in the research design and coordination, and helped to draft the manuscript. All authors read and approved the final manuscript and agree to be accountable for all aspects of the research in ensuring that the accuracy or integrity of any part of the work are appropriately investigated and resolved.

\section{Ethics approval and consent to participate}

All procedures performed in studies involving human participants were in accordance with the ethical standards of the institutional and/or national research committee and with the 1964 Helsinki declaration and its later amendments or comparable ethical standards. All participants provided written informed consent, and the study was approved by the Ethics Committee of the Affiliated Hospital of Jiangnan University (Wuxi, China).

\section{Patient consent for publication}

Not applicable.

\section{Competing interests}

The authors declare that they have no competing interests.

\section{References}

1. Ljungberg B, Bensalah K, Canfield S, Dabestani S, Hofmann F, Hora M, Kuczyk MA, Lam T, Marconi L, Merseburger AS, et al: EAU guidelines on renal cell carcinoma: 2014 update. Eur Urol 67: 913-924, 2015.

2. Patard JJ, Leray E, Rodriguez A, Rioux-Leclercq N, Guillé F and Lobel B: Correlation between symptom graduation, tumor characteristics and survival in renal cell carcinoma. Eur Urol 44: 226-232, 2003.

3. Wang M, Gao H, Qu H, Li J, Liu K and Han Z: MiR-137 suppresses tumor growth and metastasis in clear cell renal cell carcinoma. Pharmacol Rep 70: 963-971, 2018.

4. Keegan KA, Schupp CW, Chamie K, Hellenthal NJ, Evans CP and Koppie TM: Histopathology of surgically treated renal cell carcinoma: Survival differences by subtype and stage. J Urol 188: 391-397, 2012.
5. Powles T, Staehler M, Ljungberg B, Bensalah K, Canfield SE, Dabestani S, Giles R, Hofmann F, Hora M, Kuczyk MA, et al: Updated EAU guidelines for clear cell renal cancer patients who fail VEGF targeted therapy. Eur Urol 69: 4-6, 2016.

6. Berezikov E, Guryev V, van de Belt J, Wienholds E, Plasterk RH and Cuppen E: Phylogenetic shadowing and computational identification of human microRNA genes. Cell 120: 21-24, 2005.

7. Zamore PD and Haley B: Ribo-gnome: The big world of small RNAs. Science 309: 1519-1524, 2005.

8. Ying SY, Chang DC and Lin SL: The microRNA (miRNA): Overview of the RNA genes that modulate gene function. Mol Biotechnol 38: 257-268, 2008.

9. Pfeffer SR, Yang CH and Pfeffer LM: The Role of miR-21 in cancer. Drug Dev Res 76: 270-277, 2015.

10. Quan J, Jin L, Pan X, He T, Lai Y, Chen P, Lin C, Yang S, Zeng H and Lai Y: Oncogenic miR-23a-5p is associated with cellular function in RCC. Mol Med Rep 16: 2309-2317, 2017.

11. Pan X, Quan J, Li Z, Zhao L, Zhou L, Jinling X, Weijie X, Guan X, Li H, Yang S, et al: miR-566 functions as an oncogene and a potential biomarker for prognosis in renal cell carcinoma. Biomed Pharmacother 102: 718-727, 2018.

12. Quan J, Li Y, Pan X, Lai Y, He T, Lin C, Zhou L, Zhao L, Sun S, Ding Y, et al: Oncogenic miR-425-5p is associated with cellular migration, proliferation and apoptosis in renal cell carcinoma. Oncol Lett 16: 2175-2184, 2018.

13. Fu H, Tie Y, Xu C, Zhang Z, Zhu J, Shi Y, Jiang H, Sun Z and Zheng X: Identification of human fetal liver miRNAs by a novel method. FEBS Lett 579: 3849-3854, 2005.

14. Lang B and Zhao S: miR-486 functions as a tumor suppressor in esophageal cancer by targeting CDK4/BCAS2. Oncol Rep 39: 71-80, 2018.

15. Gao ZJ, Yuan WD, Yuan JQ, Yuan K and Wang Y: miR-486-5p functions as an oncogene by targeting PTEN in non-small cell lung cancer. Pathol Res Pract 214: 700-705, 2018.

16. Zhang Y, Fu J, Zhang Z and Qin H: miR-486-5p regulates the migration and invasion of colorectal cancer cells through targeting PIK3R1. Oncol Lett 15: 7243-7248, 2018.

17. He M, Wang G, Jiang L, Qiu C, Li B, Wang J and Fu Y: miR-486 suppresses the development of osteosarcoma by regulating PKC- $\delta$ pathway. Int J Oncol 50: 1590-1600, 2017.

18. Livak KJ and Schmittgen TD: Analysis of relative gene expression data using real-time quantitative PCR and the 2(-Delta Delta C(T)) method. Methods 25: 402-408, 2001.

19. Siegel RL, Miller KD and Jemal A: Cancer statistics, 2017. CA Cancer J Clin 67: 7-30, 2017.

20. Behm-Ansmant I, Rehwinkel J and Izaurralde E: MicroRNAs silence gene expression by repressing protein expression and/or by promoting mRNA decay. Cold Spring Harb Symp Quant Biol 71: 523-530, 2006.

21. Liu F, Sang M, Meng L, Gu L, Liu S, Li J and Geng C: miR-92b promotes autophagy and suppresses viability and invasion in breast cancer by targeting EZH2. Int J Oncol 53: 1505-1515, 2018.

22. Luo L, Xia L, Zha B, Zuo C, Deng D, Chen M, Hu L, He Y, Dai F, Wu J, et al: miR-335-5p targeting ICAM-1 inhibits invasion and metastasis of thyroid cancer cells. Biomed Pharmacother 106: 983-990, 2018

23. Zhang X, Yang Y and Feng Z: Suppression of microRNA-495 alleviates high-glucose-induced retinal ganglion cell apoptosis by regulating Notch/PTEN/Akt signaling. Biomed Pharmacother 106: 923-929, 2018.

24. Cao L, Wan Q, Li F and Tang CE: MiR-363 inhibits cisplatin chemoresistance of epithelial ovarian cancer by regulating snail-induced epithelial-mesenchymal transition. BMB Rep 51: 456-461, 2018.

25. Bitarte N, Bandres E, Boni V, Zarate R, Rodriguez J, Gonzalez-Huarriz M, Lopez I, Javier Sola J, Alonso MM, Fortes P and Garcia-Foncillas J: MicroRNA-451 is involved in the self-renewal, tumorigenicity, and chemoresistance of colorectal cancer stem cells. Stem Cells 29: 1661-1671, 2011.

26. Liu Y, Zhang J, Xing C, Wei S, Guo N and Wang Y: miR-486 inhibited osteosarcoma cells invasion and epithelial-mesenchymal transition by targeting PIM1. Cancer Biomark 23: 269-277, 2018.

27. Zhang X, Zhang T, Yang K, Zhang M and Wang K: miR-486-5p suppresses prostate cancer metastasis by targeting Snail and regulating epithelial-mesenchymal transition. OncoTargets Ther 9: 6909-6914, 2016.

28. Shao Y, Shen YQ, Li YL, Liang C, Zhang BJ, Lu SD, He YY, Wang $P$, Sun QL, Jin YX and Ma ZL: Direct repression of the oncogene CDK4 by the tumor suppressor miR-486-5p in non-small cell lung cancer. Oncotarget 7: 34011-34021, 2016. 
29. Goto K, Oue N, Shinmei S, Sentani K, Sakamoto N, Naito Y, Hayashi T, Teishima J, Matsubara A and Yasui W: Expression of miR-486 is a potential prognostic factor after nephrectomy in advanced renal cell carcinoma. Mol Clin Oncol 1: 235-240, 2013.

30. Jiang X, Du L, Duan W, Wang R, Yan K, Wang L, Li J, Zheng G, Zhang X, Yang Y and Wang C: Serum microRNA expression signatures as novel noninvasive biomarkers for prediction and prognosis of muscle-invasive bladder cancer. Oncotarget 7: 36733-36742, 2016

31. Ren C, Chen H, Han C, Fu D, Zhou L, Jin C, Wang F, Wang D, Chen Y, Ma L, et al: miR-486-5p expression pattern in esophageal squamous cell carcinoma, gastric cancer and its prognostic value. Oncotarget 7: 15840-15853, 2016
32. Li C, Zheng X, Li W, Bai F, Lyu J and Meng QH: Serum miR-486-5p as a diagnostic marker in cervical cancer: With investigation of potential mechanisms. BMC Cancer 18: 61 , 2018.

33. Li W, Wang Y, Zhang Q, Tang L, Liu X, Dai Y, Xiao L, Huang S, Chen L, Guo Z, et al: MicroRNA-486 as a biomarker for early diagnosis and recurrence of non-small cell lung cancer. PLoS One 10: e0134220, 2015. 